\title{
Convergence theorems for fixed points of uniformly continuous $\Phi$-pseudo-contractive-type operator
}

\author{
Charles E Chidume ${ }^{1 *}$, Ngalla Djitté1,2 and Jeremiah N Ezeora ${ }^{1,3}$
}

${ }^{*}$ Correspondence:

cchidume@aust.edu.ng

${ }^{1}$ Mathematics Institute, African

University of Science and

Technology, Abuja, Nigeria

Full list of author information is

available at the end of the article

\begin{abstract}
Let $E$ be a real normed linear space, let $K$ be a nonempty convex subset of $E$, and let $T: K \rightarrow E$ be a uniformly continuous $\Phi$-pseudo-contractive-type mapping. It is proved that both the Mann-type and Ishikawa-type iteration schemes converge strongly to the unique fixed point of $T$, without requiring that the sequences associated with the schemes be bounded. Our theorems are significant improvements on the results of Chang et al. (Iterative methods for nonlinear operators in Banach spaces, 2002), those of Gu (Northeast Math. J. 17(3):340-346, 2001), and those of a host of other authors.
\end{abstract}

MSC: 47H06; 47H09; 47J05; 47J25

Keywords: strongly pseudo-contraction maps; strongly $\phi$-accretive maps; uniformly continuous maps; generalized $\Phi$-accretive maps; generalized $\Phi$-quasi-accretive maps

\section{Introduction}

Let $E$ be a real normed linear space. A mapping $J: E \rightarrow 2^{E^{*}}$ defined by

$$
J x:=\left\{x^{*} \in E^{*}:\left\langle x, x^{*}\right\rangle=\|x\|\left\|x^{*}\right\|,\left\|x^{*}\right\|=\|x\|, x \in E\right\},
$$

where $\langle\cdot, \cdot\rangle$ denotes the duality pairing between the elements of $E$ and those of $E^{*}$, is called the normalized duality map on $E$. If $E^{*}$ is strictly convex, then $J$ is single-valued (see, e.g., [1] or [2]). An operator $A: D(A) \subseteq E \rightarrow E$ is called strongly accretive if there exists some $k>0$ such that for each $x, y \in D(A)$, there exists $j(x-y) \in J(x-y)$ such that

$$
\langle A x-A y, j(x-y)\rangle \geq k\|x-y\|^{2} .
$$

The mapping $A$ is said to be strongly $\phi$-accretive if there exists a strictly increasing function $\phi:[0, \infty) \rightarrow[0, \infty)$ with $\phi(0)=0$ such that for any $x, y \in D(A)$, there exists $j(x-y) \in J(x-y)$ satisfying

$$
\langle A x-A y, j(x-y)\rangle \geq \phi(\|x-y\|)\|x-y\| .
$$

The mapping $A$ is called generalized $\Phi$-accretive if there exists a strictly increasing function $\Phi:[0, \infty) \rightarrow[0, \infty)$ with $\Phi(0)=0$ such that for any $x, y \in D(A)$, there exists $j(x-y) \in$

@2013 Chidume et al.; licensee Springer. This is an Open Access article distributed under the terms of the Creative Commons Attribution License (http://creativecommons.org/licenses/by/2.0), which permits unrestricted use, distribution, and reproduction in any medium, provided the original work is properly cited. 
$J(x-y)$ satisfying

$$
\langle A x-A y, j(x-y)\rangle \geq \Phi(\|x-y\|)
$$

It is well known that the class of generalized $\Phi$-accretive mappings includes the class of strongly $\phi$-accretive operators as a special case (one sets $\Phi(s)=s \phi(s)$ for all $s \in[0, \infty)$ ).

Let $N(A):=\{x \in E: A x=0\} \neq \emptyset$. The mapping $A$ is called strongly quasi-accretive if there exists $k \in(0,1)$ such that for all $x \in D(A), x^{*} \in N(A)$, there exists $j\left(x-x^{*}\right) \in J\left(x-x^{*}\right)$ satisfying

$$
\left\langle A x-A x^{*}, j\left(x-x^{*}\right)\right\rangle \geq k\left\|x-x^{*}\right\|^{2}
$$

$A$ is called strongly $\phi$-quasi-accretive if there exists a strictly increasing function $\phi$ : $[0, \infty) \rightarrow[0, \infty)$ with $\phi(0)=0$ such that for all $x \in D(A), x^{*} \in N(A)$, there exists $j\left(x-x^{*}\right) \in$ $J\left(x-x^{*}\right)$ satisfying

$$
\left\langle A x-A x^{*}, j\left(x-x^{*}\right)\right\rangle \geq \phi\left(\left\|x-x^{*}\right\|\right)\left\|x-x^{*}\right\| .
$$

Finally, $A$ is called generalized $\Phi$-quasi-accretive if there exists a strictly increasing function $\Phi:[0, \infty) \rightarrow[0, \infty)$ with $\Phi(0)=0$ such that for all $x \in E, x^{*} \in N(A)$, there exists $j\left(x-x^{*}\right) \in J\left(x-x^{*}\right)$ satisfying

$$
\left\langle A x-A x^{*}, j\left(x-x^{*}\right)\right\rangle \geq \Phi\left(\left\|x-x^{*}\right\|\right) .
$$

A mapping $T: E \rightarrow E$ is called strongly pseudo-contractive if for all $x, y \in E$, the following inequality holds:

$$
\|x-y\| \leq\|(1+r)(x-y)-r t(T x-T y)\|
$$

for all $r>0$ and some $t>1$. If $t=1$ in inequality (1.7), then $T$ is called pseudo-contractive. The relation between the class of accretive-type mappings and those of pseudo-contractive type is contained in the following proposition.

Proposition 1.1 A mapping $T: E \rightarrow E$ is strongly pseudo-contractive if and only if $(I-T)$ is strongly accretive, and is strongly $\phi$-pseudo-contractive if and only if $(I-T)$ is strongly $\phi$-accretive. The mapping $T$ is generalized $\Phi$-pseudo-contractive if and only if $(I-T)$ is generalized $\Phi$-accretive.

Proposition 1.2 If $F(T):=\{x \in E: T x=x\} \neq \emptyset$, the mapping $T$ is strongly hemi-contractive if and only if $(I-T)$ is strongly quasi-accretive; it is $\phi$-hemi-contractive if and only if $(I-T)$ is strongly $\phi$-quasi-accretive; and $T$ is generalized $\Phi$-hemi-contractive if and only if $(I-T)$ is generalized $\Phi$-quasi-accretive.

The class of generalized $\Phi$-hemi-contractive mappings is the most general (among those defined above) for which $T$ has a unique fixed point. 
Numerous convergence results have been proved on iterative methods for approximating zeros of Lipschitz $\Phi$-strongly accretive type (or fixed points of $\Phi$-strongly pseudocontractive type) nonlinear mappings and their stability (see, e.g., Chang et al. [3], Chidume [4, 5], Chidume and Zegeye [6], Deng and Ding [7], Shahzad and Zegeye [8] and the references contained therein). Also, many authors have proved convergence theorems under the assumption that these operators have bounded range (see, e.g., Browder and Petryshyn [9], Hirano and Huang [10] and the references contained therein).

Some of these results have been extended to uniformly continuous mappings. The most general results for uniformly continuous $\Phi$-pseudo-contractive-type and $\phi$-hemicontractive-type mappings seem to be the following theorems (see also [2], Chapter 9).

Theorem G1 ([11], Theorem 2.1) Let E be a real normed linear space, let $K$ be a nonempty subset of $E$, and let $T: K \rightarrow E$ be a uniformly continuous $\Phi$-pseudo-contractive-type operator, i.e., there exist $x^{*} \in K$ and a strictly increasing function $\Phi:[0, \infty) \rightarrow[0, \infty), \Phi(0)=0$ such that for all $x \in K$, there exists $j\left(x-x^{*}\right) \in J\left(x-x^{*}\right)$ satisfying

$$
\left\langle T x-x^{*}, j\left(x-x^{*}\right)\right\rangle \leq\left\|x-x^{*}\right\|^{2}-\Phi\left(\left\|x-x^{*}\right\|\right) .
$$

(a) If $y^{*} \in K$ is a fixed point of $T$, then $y^{*}=x^{*}$, and so $T$ has at most one fixed point in $K$; (b) Suppose that there exists $x_{0} \in K$ such that both the Ishikawa iterative sequence $\left\{x_{n}\right\}$ with error and the auxiliary sequence $\left\{y_{n}\right\}$ defined by

$$
\begin{aligned}
& y_{n}=\left(1-\beta_{n}\right) x_{n}+\beta_{n} T x_{n}+v_{n}, \quad n \geq 0, \\
& x_{n+1}=\left(1-\alpha_{n}\right) x_{n}+\alpha_{n} T y_{n}+u_{n},
\end{aligned}
$$

are contained in $K$, where $\left\{u_{n}\right\},\left\{v_{n}\right\}$ are two sequences in $E$ and $\left\{\alpha_{n}\right\},\left\{\beta_{n}\right\}$ are two sequences in $[0,1]$ satisfying the following conditions: (i) $\alpha_{n}, \beta_{n} \rightarrow 0(n \rightarrow \infty)$ and $\sum \alpha_{n}=\infty$; (ii) $\left\|u_{n}\right\|=o\left(\alpha_{n}\right)$ and $\left\|v_{n}\right\| \rightarrow 0(n \rightarrow \infty)$. If $\left\{x_{n}\right\}$ is a bounded sequence in $K$, then $\left\{x_{n}\right\}$ converges strongly to $x^{*}$. In particular, if $y^{*}$ is a fixed point of $T$ in $K$, then $\left\{x_{n}\right\}$ converges strongly to $y^{*}$.

Theorem G2 ([11], Theorem 2.2) Let E be a real normed linear space, let $K$ be a nonempty subset of $E$ such that $K+K \subset K$. Let $T: K \rightarrow K$ be a uniformly continuous $\Phi$-pseudocontractive-type operator.

Let $\left\{u_{n}\right\},\left\{v_{n}\right\},\left\{\alpha_{n}\right\},\left\{\beta_{n}\right\}$ be as in Theorem G1. For any given $x_{0} \in K$, the Ishikawa iterative sequence $\left\{x_{n}\right\}$ with errors is defined as in Theorem G1. (a) If $y^{*} \in K$ is a fixed point of $T$, then $y^{*}=x^{*}$, and so Thas at most one fixed point in $K$; (b) If $\left\{x_{n}\right\}$ is a bounded sequence, then $\left\{x_{n}\right\}$ converges strongly to $x^{*}$. In particular, if $y^{*}$ is a fixed point of $T$ in $K$, then $\left\{x_{n}\right\}$ converges strongly to $y^{*}$.

Theorem CCZ1 ([3], Theorem 7.2.1) Let E be a real normed linear space, let $K$ be a nonempty convex subset of $E$ such that $K+K \subset K$, and let $T: K \rightarrow K$ be a uniformly continuous and $\phi$-hemi-contractive mapping. Let $\left\{\alpha_{n}\right\},\left\{\beta_{n}\right\}$ be two real sequences in $(0,1)$ satisfying the following conditions: (i) $\alpha_{n}, \beta_{n} \rightarrow 0(n \rightarrow \infty)$; (ii) $\sum \alpha_{n}=\infty$. Assume that $\left\{u_{n}\right\},\left\{v_{n}\right\}$ are two sequences in $K$ satisfying the following conditions: $u_{n}=u_{n}^{\prime}+u_{n}^{\prime \prime}$ for any 
sequences $\left\{u_{n}^{\prime}\right\},\left\{u_{n}^{\prime \prime}\right\}$ in $K$ with $\sum\left\|u_{n}^{\prime}\right\|<\infty ;\left\|u_{n}^{\prime \prime}\right\|=o\left(\alpha_{n}\right)$ and $\left\|v_{n}\right\| \rightarrow 0$ as $n \rightarrow \infty$. Define the Ishikawa iterative sequence with mixed errors in $K$ by

$$
\begin{aligned}
& y_{n}=\left(1-\beta_{n}\right) x_{n}+\beta_{n} T x_{n}+v_{n}, \quad n \geq 0, \\
& x_{n+1}=\left(1-\alpha_{n}\right) x_{n}+\alpha_{n} T y_{n}+u_{n} .
\end{aligned}
$$

If $\left\{T y_{n}\right\}$ is bounded, then the sequence $\left\{x_{n}\right\}$ converges strongly to the unique fixed point of $T$.

Theorem CCZ2 ([3], Theorem 7.2.2) Let $E$ be a real normed linear space, and let $T: E \rightarrow$ $E$ be a uniformly continuous and strongly $\phi$-quasi-accretive mapping. Let $\left\{\alpha_{n}\right\},\left\{\beta_{n}\right\}$ be two real sequences in $(0,1)$ satisfying the following conditions:
(i) $\quad \alpha_{n}, \beta_{n} \rightarrow 0 \quad(n \rightarrow \infty)$;
(ii) $\sum \alpha_{n}=\infty$

Let $\left\{u_{n}\right\},\left\{v_{n}\right\}$ be as in Theorem CCZ1. Define a mapping $S: E \rightarrow E$ by $S x:=x-$ Tx for each $x \in E$. For an arbitrary $x_{0} \in E$, define the Ishikawa iterative sequence $\left\{x_{n}\right\}$ with mixed errors by

$$
\begin{aligned}
& y_{n}=\left(1-\beta_{n}\right) x_{n}+\beta_{n} T x_{n}+v_{n}, \quad n \geq 0, \\
& x_{n+1}=\left(1-\alpha_{n}\right) x_{n}+\alpha_{n} T y_{n}+u_{n} .
\end{aligned}
$$

If $\left\{S y_{n}\right\}$ is bounded, then the sequence $\left\{x_{n}\right\}$ converges strongly to the unique fixed point of $T$.

Remark 1.3 Theorems G1, G2, CCZ1 and CCZ2 are important generalizations of several results. We observe that the class of mappings considered in Theorems CCZ1 and CCZ2 is a proper subclass of the class of mappings studied in Theorems G1 and G2 in which $\Phi(s)=s \phi(s)$. However, the requirement that $\left\{x_{n}\right\}$ be bounded imposed in Theorems G1 and G2 is stronger than the requirement that $\left\{T y_{n}\right\}$ or $\left\{S y_{n}\right\}$ be bounded imposed in Theorems CCZ1 and CCZ2, respectively.

In Theorems G1 and G2 of [11], convergence of $\left\{x_{n}\right\}$ under other conditions of the theorems is guaranteed if the sequence $\left\{x_{n}\right\}$ is bounded.

Remark 1.4 Similarly, the sequence $\left\{x_{n}\right\}$ defined in Theorem CCZ1 is guaranteed to converge if $\left\{T y_{n}\right\}$ is bounded. Finally, the sequence $\left\{x_{n}\right\}$ defined in CCZ2 is guaranteed to converge if $\left\{S y_{n}\right\}$ is bounded. The requirements that $\left\{x_{n}\right\},\left\{T y_{n}\right\}$ and $\left\{S y_{n}\right\}$ be bounded before convergence in these theorems is guaranteed is a huge constraint in any possible application of these theorems. The verifications that these sequences are bounded are, in general, very difficult.

It is our purpose in this paper to prove that, under the hypotheses of these theorems, the requirements that $\left\{x_{n}\right\},\left\{T y_{n}\right\}$ and $\left\{S y_{n}\right\}$ be bounded can be dispensed with. In fact, we prove that these sequences are necessarily bounded. We achieve this by using the lemma recently proved by Chidume and Chidume [12]. 


\section{Preliminaries}

In the sequel, we shall make use of the following results.

Lemma 2.1 Let $E$ be a real normed linear space, and let $J: E \rightarrow 2^{E^{*}}$ be the normalized duality map. Then, for any $x, y \in E$, there exists $j(x+y) \in J(x+y)$ such that the following inequality holds:

$$
\|x+y\|^{2} \leq\|x\|^{2}+2\langle y, j(x+y)\rangle
$$

Lemma 2.2 (Chidume and Chidume, [12]) Let $X$ and $Y$ be real normed linear spaces, and let $T: X \rightarrow Y$ be uniformly continuous. For arbitrary $r>0$ and fixed $x^{*} \in X$, let

$$
B_{X}\left(x^{*}, r\right):=\left\{x \in X:\left\|x-x^{*}\right\| \leq r\right\} .
$$

Then $T\left(B\left(x^{*}, r\right)\right)$ is bounded.

Since this lemma is new and is yet to be published, we reproduce its short proof here.

Proof By uniform continuity of $T$ and by taking $\epsilon=1$, there exists $\delta>0$ such that for all $x, y \in X$,

$$
\|x-y\|<\delta \quad \Rightarrow \quad\|T x-T y\|<1
$$

For $r>0$, let $z \in B\left(x^{*}, r\right)$ be arbitrary. Choose $n_{0} \in \mathbb{N}$ fixed such that $r<n_{0} \delta$.

$$
\begin{aligned}
& \text { Set } z_{1}=x^{*}+\frac{z-x^{*}}{n_{0}}, z_{2}=x^{*}+\frac{2\left(z-x^{*}\right)}{n_{0}}, z_{3}=x^{*}+\frac{3\left(z-x^{*}\right)}{n_{0}}, \ldots, z_{k}=x^{*}+\frac{k\left(z-x^{*}\right)}{n_{0}}, z_{k+1}=x^{*}+\frac{(k+1)\left(z-x^{*}\right)}{n_{0}}, \\
& \ldots, z_{n_{0}-1}=x^{*}+\frac{\left(n_{0}-1\right)\left(z-x^{*}\right)}{n_{0}}, z_{n_{0}}=z \text {. Then } \\
& \left\|z_{k+1}-z_{k}\right\|=\frac{\left\|z-x^{*}\right\|}{n_{0}} \leq \frac{r}{n_{0}}<\delta .
\end{aligned}
$$

By uniform continuity of $T,\left\|T z_{k+1}-T z_{k}\right\|<1$. Furthermore,

$$
\begin{aligned}
\|T z\|= & \left\|T z_{n_{0}}\right\| \leq\left\|T z_{n_{0}}-T z_{n_{0}-1}\right\|+\left\|T z_{n_{0}-1}-T z_{n_{0}-2}\right\|+\cdots \\
& +\left\|T z_{2}-T z_{1}\right\|+\left\|T z_{1}\right\| \leq n_{0}+\left\|T z_{1}\right\| .
\end{aligned}
$$

Hence, $T\left(B\left(x^{*}, r\right)\right)$ is bounded.

\section{Main result}

Theorem 3.1 Let $E$ be a real normed linear space, let $K$ be a nonempty subset of $E$, and let $T: K \rightarrow E$ be a uniformly continuous $\Phi$-pseudo-contractive-type operator. Suppose that $\left\{x_{n}\right\}_{n=0}^{\infty}$ is as defined in Theorem G1, then there exists $\gamma_{0}>0$ such that if $\alpha_{n}, \beta_{n}, \frac{\left\|u_{n}\right\|}{\alpha_{n}} \leq \gamma_{0}$ $\forall n \geq 0$, then $\left\{x_{n}\right\}$ is bounded.

Proof We have

$$
\begin{aligned}
& y_{n}=\left(1-\beta_{n}\right) x_{n}+\beta_{n} T x_{n}+v_{n}, \\
& x_{n+1}=\left(1-\alpha_{n}\right) x_{n}+\alpha_{n} T y_{n}+u_{n}, \quad n \geq 0 .
\end{aligned}
$$


Let $x_{0} \in K$ be as defined in Theorem G1 with $x_{0} \neq x^{*}$. Define

$$
a_{0}:=\left\|x_{0}-T x_{0}\right\| \cdot\left\|x_{0}-x^{*}\right\|+1>0
$$

Then from (1.8) we obtain that $\left\|x_{0}-x^{*}\right\| \leq \Phi^{-1}\left(a_{0}\right)$.

Observe that since $\left\{u_{n}\right\}_{n=0}^{\infty}$ and $\left\{v_{n}\right\}_{n=0}^{\infty}$ are bounded, $u_{n}, v_{n} \in B\left(x^{*}, r\right) n \geq 0$ for some $r>0$. Let

$$
R=4 \Phi^{-1}\left(a_{0}\right)+2\left\|T x^{*}\right\|+3\left\|x^{*}\right\|+\sigma
$$

where $\sigma=\operatorname{diam}(T(B))+r, B=B\left(x^{*}, 2 \Phi^{-1}\left(a_{0}\right)\right)$. Set

$$
\begin{aligned}
& M_{0}=\sup \left\{\|\xi-T \zeta\|+\|\xi-\zeta\|: \xi, \zeta \in B\left(x^{*}, R\right)\right\} \\
& \rho_{0}=\left(M_{0}+1\right), \quad \rho_{1}=24\left(M_{0}+1\right) \Phi^{-1}\left(a_{0}\right), \\
& \rho_{2}=4\left(M_{0}+1\right)
\end{aligned}
$$

and

$$
\epsilon_{0}:=\frac{\Phi\left(2 \Phi^{-1}\left(a_{0}\right)\right)}{12 \Phi^{-1}\left(a_{0}\right)} .
$$

By uniform continuity of $T$, there exists $\delta=\delta\left(\epsilon_{0}\right)>0$ such that $\|x-y\|<\delta \Rightarrow\|T x-T y\|<\epsilon_{0}$.

Define

$$
\gamma_{0}=\frac{1}{2} \min \left\{1, \frac{\Phi^{-1}\left(a_{0}\right)}{\rho_{0}}, \frac{\Phi\left(2 \Phi^{-1}\left(a_{0}\right)\right)}{\rho_{1}}, \frac{\delta}{\rho_{2}}\right\} .
$$

Claim $\left\|x_{n}-x^{*}\right\| \leq 2 \Phi^{-1}\left(a_{0}\right) \forall n \geq 0$.

The proof of this claim is by induction. Clearly it holds for $n=0$. Assume it holds for some $n \geq 0$, i.e., $\left\|x_{n}-x^{*}\right\| \leq 2 \Phi^{-1}\left(a_{0}\right)$. We prove that $\left\|x_{n+1}-x^{*}\right\| \leq 2 \Phi^{-1}\left(a_{0}\right)$. Suppose this is not the case. Then $\left\|x_{n+1}-x^{*}\right\|>2 \Phi^{-1}\left(a_{0}\right)$. This implies that $\Phi\left(\left\|x_{n+1}-x^{*}\right\|\right)>$ $\Phi\left(2 \Phi^{-1}\left(a_{0}\right)\right)$.

We compute as follows:

$$
\begin{aligned}
\left\|x_{n+1}-x^{*}\right\| & \leq\left\|x_{n}-x^{*}\right\|+\alpha_{n}\left\|x_{n}-T y_{n}\right\|+\left\|u_{n}\right\| \\
& \leq 2 \Phi^{-1}\left(a_{0}\right)+\gamma_{0} M_{0}+\alpha_{n} \gamma_{0} \leq 2 \Phi^{-1}\left(a_{0}\right)+\gamma_{0}\left(M_{0}+\gamma_{0}\right) \\
& \leq 2 \Phi^{-1}\left(a_{0}\right)+\gamma_{0}\left(M_{0}+1\right)<3 \Phi^{-1}\left(a_{0}\right) \\
\left\|x_{n+1}-x_{n}\right\| & \leq \alpha_{n}\left\|x_{n}-T y_{n}\right\|+\left\|u_{n}\right\| \leq \alpha_{n}\left(M_{0}+\gamma_{0}\right) \\
& \leq \gamma_{0}\left(M_{0}+1\right), \\
\left\|x_{n+1}-y_{n}\right\| & \leq\left\|x_{n+1}-x_{n}\right\|+\left\|x_{n}-y_{n}\right\| \leq 2 \gamma_{0} M_{0}+\gamma_{0}\left(M_{0}+\gamma_{0}\right) \\
& \leq 2 \gamma_{0}\left(M_{0}+1\right)+\gamma_{0}\left(M_{0}+1\right)=3 \gamma_{0}\left(M_{0}+1\right)<\delta .
\end{aligned}
$$


Hence, $\left\|T x_{n+1}-T y_{n}\right\|<\epsilon_{0}$. Now,

$$
\begin{aligned}
\left\|x_{n+1}-x^{*}\right\|^{2}= & \left\|\left(x_{n}-x^{*}\right)-\left[\alpha_{n}\left(x_{n}-T y_{n}\right)-u_{n}\right]\right\|^{2} \\
\leq & \left\|x_{n}-x^{*}\right\|^{2}-2 \alpha_{n}\left\langle x_{n}-T y_{n}, j\left(x_{n+1}-x^{*}\right)\right\rangle \\
& +2\left\|u_{n}\right\| \cdot\left\|x_{n+1}-x^{*}\right\| \\
\leq & \left\|x_{n}-x^{*}\right\|^{2}-2 \alpha_{n}\left[\Phi\left(\left\|x_{n+1}-x^{*}\right\|\right)\right] \\
& +2 \alpha_{n}\left[\left\|x_{n+1}-x^{*}\right\| \cdot\left\|x_{n+1}-x_{n}\right\|\right. \\
& \left.+\left\|T x_{n+1}-T y_{n}\right\| \cdot\left\|x_{n+1}-x^{*}\right\|\right]+2\left\|u_{n}\right\| \cdot\left\|x_{n+1}-x^{*}\right\| \\
< & \left\|x_{n}-x^{*}\right\|^{2}-2 \alpha_{n} \Phi\left(2 \Phi^{-1}\left(a_{0}\right)\right)+2 \alpha_{n}\left[3 \Phi^{-1}\left(a_{0}\right) \cdot \gamma_{0}\left(M_{0}+1\right)\right. \\
& \left.+\epsilon_{0} \cdot 3 \Phi^{-1}\left(a_{0}\right)\right]+2 \alpha_{n} \gamma_{0} 3 \Phi^{-1}\left(a_{0}\right) \\
\leq & \left\|x_{n}-x^{*}\right\|^{2}-2 \alpha_{n} \Phi\left(2 \Phi^{-1}\left(a_{0}\right)\right) \\
& +2 \alpha_{n}\left[\frac{1}{4} \Phi\left(2 \Phi^{-1}\left(a_{0}\right)\right)+\frac{1}{4} \Phi\left(2 \Phi^{-1}\left(a_{0}\right)\right)\right]+2 \alpha_{n} \gamma_{0} 3 \Phi^{-1}\left(a_{0}\right), \\
< & \left\|x_{n}-x^{*}\right\|^{2}, \quad \text { using the definition of } \gamma_{0} .
\end{aligned}
$$

Hence, $\left\|x_{n+1}-x^{*}\right\|<\left\|x_{n}-x^{*}\right\| \leq 2 \Phi^{-1}\left(a_{0}\right)$, a contradiction. So, $\left\{x_{n}\right\}$ is bounded.

Corollary 3.2 (Theorem G1 ([11], Theorem 2.1)) Let E be a real normed linear space, let $K$ be a nonempty subset of $E$, and let $T: K \rightarrow E$ be a uniformly continuous $\Phi$-pseudocontractive-type operator, i.e., there exist $x^{*} \in K$ and a strictly increasing function $\Phi$ : $[0, \infty) \rightarrow[0, \infty), \Phi(0)=0$ such that for all $x \in K$, there exists $j\left(x-x^{*}\right) \in J\left(x-x^{*}\right)$ satisfying

$$
\left\langle T x-x^{*}, j\left(x-x^{*}\right)\right\rangle \leq\left\|x-x^{*}\right\|^{2}-\Phi\left(\left\|x-x^{*}\right\|\right)
$$

(a) If $y^{*} \in K$ is a fixed point of $T$, then $y^{*}=x^{*}$, and so $T$ has at most one fixed point in $K$; (b) Suppose that there exists $x_{0} \in K$ such that both the Ishikawa iterative sequence $\left\{x_{n}\right\}$ with error and the auxiliary sequence $\left\{y_{n}\right\}$, defined by

$$
\begin{aligned}
& y_{n}=\left(1-\beta_{n}\right) x_{n}+\beta_{n} T x_{n}+v_{n}, \quad n \geq 0, \\
& x_{n+1}=\left(1-\alpha_{n}\right) x_{n}+\alpha_{n} T y_{n}+u_{n},
\end{aligned}
$$

are contained in $K$, where $\left\{u_{n}\right\},\left\{v_{n}\right\}$ are two sequences in $E$ and $\left\{\alpha_{n}\right\},\left\{\beta_{n}\right\}$ are two sequences in $[0,1]$ satisfying the following conditions: (i) $\alpha_{n}, \beta_{n} \rightarrow 0(n \rightarrow \infty)$ and $\sum \alpha_{n}=\infty$; (ii) $\left\|u_{n}\right\|=o\left(\alpha_{n}\right)$ and $\left\|v_{n}\right\| \rightarrow 0(n \rightarrow \infty)$. Then there exists $\gamma_{0}>0$ such that if $\alpha_{n}, \beta_{n}, \frac{\left\|u_{n}\right\|}{\alpha_{n}} \leq \gamma_{0}$ $\forall n \geq 0,\left\{x_{n}\right\}$ converges strongly to $x^{*}$. In particular, if $y^{*}$ is a fixed point of $T$ in $K$, then $\left\{x_{n}\right\}$ converges strongly to $y^{*}$.

Proof Observe that Corollary 3.2 is the same as Theorem G1 without boundedness assumption on the sequence $\left\{x_{n}\right\}$ but with the assumption that there exists $\gamma_{0}>0$ such that $\alpha_{n}, \beta_{n}, \frac{\left\|u_{n}\right\|}{\alpha_{n}} \leq \gamma_{0} \forall n \geq 0$ made in Corollary 3.2. The proof that $\left\{x_{n}\right\}$ is bounded follows from Theorem 3.1. The rest of the proof of convergence is as in Theorem G1. This completes the proof. 
Theorem 3.3 Let $E$ be a real normed linear space, let $K$ be a nonempty convex subset of $E$ such that $K+K \subset K$, and let $T: K \rightarrow K$ be a uniformly continuous and $\phi$-hemi-contractive mapping. Suppose that $\left\{x_{n}\right\}_{n=0}^{\infty}$ is as defined in Theorem CCZ1 [3], then there exists $\gamma_{0}>0$ such that if $\alpha_{n}, \beta_{n}, \frac{\left\|u_{n}\right\|}{\alpha_{n}} \leq \gamma_{0} \forall n \geq 0,\left\{T y_{n}\right\}$ is bounded.

Proof The boundedness of $\left\{x_{n}\right\}$ in Theorem 3.3 follows as in Theorem 3.1. Since $\left\{x_{n}\right\}$ is bounded, by Lemma 2.2 and the uniform continuity of $T,\left\{T x_{n}\right\}$ is bounded. This with the boundedness of $\left\{v_{n}\right\}$ implies, from the relation $y_{n}:=\left(1-\beta_{n}\right) x_{n}+\beta_{n} T x_{n}+c_{n} V_{n}$, that $\left\{y_{n}\right\}$ is bounded. Again, by the uniform continuity of $T$ and Lemma 2.2, $\left\{T y_{n}\right\}$ is bounded.

Corollary 3.4 (Theorem CCZ1, [3]) Let $E$ be a real normed linear space, let $K$ be a nonempty convex subset of $E$ such that $K+K \subset K$, and let $T: K \rightarrow K$ be a uniformly continuous and $\phi$-hemi-contractive mapping. Let $\left\{\alpha_{n}\right\},\left\{\beta_{n}\right\}$ be two real sequences in $(0,1)$ satisfying the following conditions: (i) $\alpha_{n}, \beta_{n} \rightarrow 0(n \rightarrow \infty)$; (ii) $\sum \alpha_{n}=\infty$. Assume that $\left\{u_{n}\right\},\left\{v_{n}\right\}$ are two sequences in $K$ satisfying the following conditions: $u_{n}=u_{n}^{\prime}+u_{n}^{\prime \prime}$ for any sequences $\left\{u_{n}^{\prime}\right\},\left\{u_{n}^{\prime \prime}\right\}$ in $K$ with $\sum\left\|u_{n}^{\prime}\right\|<\infty ;\left\|u_{n}^{\prime \prime}\right\|=o\left(\alpha_{n}\right)$ and $\left\|v_{n}\right\| \rightarrow 0$ as $n \rightarrow \infty$. Define the Ishikawa iterative sequence with mixed errors in $K$ by

$$
\begin{aligned}
& y_{n}=\left(1-\beta_{n}\right) x_{n}+\beta_{n} T x_{n}+v_{n}, \quad n \geq 0, \\
& x_{n+1}=\left(1-\alpha_{n}\right) x_{n}+\alpha_{n} T y_{n}+u_{n} .
\end{aligned}
$$

If $\left\{T y_{n}\right\}$ is bounded, then the sequence $\left\{x_{n}\right\}$ converges strongly to the unique fixed point of $T$.

Proof Corollary 3.3 is the same as Theorem CCZ1 but without boundedness assumption on the sequence $\left\{T y_{n}\right\}$ but with the assumption that there exists $\gamma_{0}>0$ such that $\alpha_{n}, \beta_{n}, \frac{\left\|u_{n}\right\|}{\alpha_{n}} \leq \gamma_{0} \forall n \geq 0$ made in Corollary 3.3. The proof that $\left\{T y_{n}\right\}$ is bounded follows from Theorem 3.3. The remaining proof of convergence is as in Theorem CCZ1. This completes the proof.

Theorem 3.5 Let $E$ be a real normed linear space, and $T: E \rightarrow E$ be a uniformly continuous and strongly $\phi$-quasi-accretive mapping. Define a mapping $S: E \rightarrow E$ by $S x:=x-T x$ for each $x \in E$. Suppose that $\left\{x_{n}\right\}$ is as defined in Theorem CCZ2 [3], then there exists $\gamma_{0}>0$ such that if $\alpha_{n}, \beta_{n}, \frac{\left\|u_{n}\right\|}{\alpha_{n}} \leq \gamma_{0} \forall n \geq 0,\left\{S y_{n}\right\}$ is bounded.

Proof $S y_{n}:=y_{n}-T y_{n}$. Using the boundedness of $\left\{y_{n}\right\}$ and $\left\{T y_{n}\right\}$, we have that $\left\{S y_{n}\right\}$ is bounded.

Corollary 3.6 (Theorem CCZ2, [3]) Let E be a real normed linear space, and let $T: E \rightarrow E$ be a uniformly continuous and strongly $\phi$-quasi-accretive mapping. Let $\left\{\alpha_{n}\right\},\left\{\beta_{n}\right\}$ be two real sequences in $(0,1)$ satisfying the following conditions:
(i) $\quad \alpha_{n}, \beta_{n} \rightarrow 0 \quad(n \rightarrow \infty)$;
(ii) $\sum \alpha_{n}=\infty$

Let $\left\{u_{n}\right\},\left\{v_{n}\right\}$ be as in Theorem CCZ1. Define a mapping $S: E \rightarrow E$ by Sx $:=x-$ Tx for each $x \in E$. For an arbitrary $x_{0} \in E$, define the Ishikawa iterative sequence $\left\{x_{n}\right\}$ with mixed 
errors by

$$
\begin{aligned}
& y_{n}=\left(1-\beta_{n}\right) x_{n}+\beta_{n} T x_{n}+v_{n}, \quad n \geq 0, \\
& x_{n+1}=\left(1-\alpha_{n}\right) x_{n}+\alpha_{n} T y_{n}+u_{n} .
\end{aligned}
$$

If $\left\{S y_{n}\right\}$ is bounded, then the sequence $\left\{x_{n}\right\}$ converges strongly to the unique fixed point of $T$.

Proof Corollary 3.5 is the same as Theorem CCZ2 without boundedness assumption on the sequence $\left\{S y_{n}\right\}$ but with the assumption that there exists $\gamma_{0}>0$ such that $\alpha_{n}, \beta_{n}, \frac{\left\|u_{n}\right\|}{\alpha_{n}} \leq$ $\gamma_{0} \forall n \geq 0$ made in Corollary 3.5. The proof that $\left\{S y_{n}\right\}$ is bounded follows from Theorem 3.5. The rest of the proof of convergence is as in Theorem CCZ2. This completes the proof.

Remark 3.7 Theorem 3.4 shows that Theorems G1 and G2 remain valid without the requirement that $\left\{x_{n}\right\}$ be bounded. Also, it shows that Theorems CCZ1 and CCZ2 remain valid without the requirement that $\left\{T y_{n}\right\}$ and $\left\{S y_{n}\right\}$ be bounded, respectively.

Remark 3.8 Part of the aim of including bounded error terms in recursion formulas of Theorem 3.1 and Corollaries 3.4 and 3.6 is to illustrate the fact that if the theorems are proved without these error terms, then addition of bounded error terms in the recursion formulas leads to no generalization. The proof in the case with error terms is in general an unnecessary repetition of the proof using recursion formulas without error terms (see Chapter 9 of [2]).

Prototype An example of iteration parameters satisfying the conditions of our theorems is as follows:

$$
\alpha_{n}=\beta_{n}=\frac{\gamma_{0}}{\sqrt{n}}, \quad n \geq 1
$$

\section{Competing interests}

The authors declare that there are no competing interests.

Authors' contributions

All authors contributed equally. All authors read and approved the final manuscript.

\section{Author details}

${ }^{1}$ Mathematics Institute, African University of Science and Technology, Abuja, Nigeria. ${ }^{2}$ Université Gaston Berger, Saint Louis, Sénégal. ${ }^{3}$ Department of Ind. Maths and Statistics, Ebonyi State University, Abakaliki, Nigeria.

\section{Acknowledgements}

The third author's research is supported by the Ebonyi State University, Abakaliki, Nigeria under the ETF PhD Scholarship.

Received: 2 June 2013 Accepted: 18 October 2013 Published: 25 Nov 2013

\section{References}

1. Berinde, V: Iterative Approximation of Fixed Points. Lecture Notes in Mathematics, vol. 1912. Springer, Berlin (2007)

2. Chidume, C: Geometric Properties of Banach Spaces and Nonlinear Iterations. Lecture Notes in Mathematics, vol. 1965 (2009). ISBN:978-1-84882-189-7

3. Chang, SS, Cho, YJ, Zhou, H: Iterative Methods for Nonlinear Operators in Banach Spaces. Nova Science Publishers, New York (2002)

4. Chidume, CE: Iterative methods for nonlinear Lipschitz pseudo-contractive operators. J. Math. Anal. Appl. 251(1), 84-92 (2000) 
5. Chidume, CE: Iterative approximation of fixed point of Lipschitz pseudo-contractive operators. Proc. Am. Math. Soc 129(8), 2245-2251 (2001)

6. Chidume, $\mathrm{CE}$, Zegeye, $\mathrm{H}$ : Approximate fixed point sequences and convergence theorems for Lipschitz pseudo-contractive maps. Proc. Am. Math. Soc. 132(3), 831-840 (2004)

7. Ding, XP: Iterative approximation of Lipschitz strictly pseudocontractive mappings in uniformly smooth Banach spaces. Nonlinear Anal. 24(7), 981-987 (1995)

8. Shazad, N, Zegeye, H: On stability for $\phi$-strongly pseudocontractive mappings. Nonlinear Anal. 64(2), 2619-2630 (2006)

9. Browder, FE, Petryshyn, WV: Construction of fixed points of nonlinear mappings in Hilbert spaces. J. Math. Anal. Appl. 20, 197-228 (1967)

10. Hirano, H, Huang, Z: Convergence theorems for multi-valued $\Phi$-hemicontractive operators and $\Phi$-strongly accretive operators. Comput. Math. Appl. 46(10-11), 1461-1471 (2003)

11. Gu, F: Convergence theorems for $\Phi$-pseudo-contractive-type mappings in normed linear spaces. Northeast. Math. J. 17(3), 340-346 (2001)

12. Chidume, $C E$, Chidume, CO: A convergence theorem for zeros of generalized $\Phi$-quasi-accretive mappings (to appear)

10.1186/1687-1812-2013-321

Cite this article as: Chidume et al.: Convergence theorems for fixed points of uniformly continuous

$\Phi$-pseudo-contractive-type operator. Fixed Point Theory and Applications 2013, 2013:321

\section{Submit your manuscript to a SpringerOpen ${ }^{0}$ journal and benefit from:}

- Convenient online submission

- Rigorous peer review

- Immediate publication on acceptance

- Open access: articles freely available online

- High visibility within the field

- Retaining the copyright to your article 